\title{
Developing Academic, Professional and Life Skills in Undergraduate Engineers through an Interdisciplinary Peer-Mentoring Support System
}

\author{
Deborah Nykanen, Rebecca Bates, Marilyn Hart, Mezbahur Rahman \\ Minnesota State University, Mankato \\ Civil Engineering / Computer Science / Biological Sciences / Mathematics
}

\section{Introduction}

Undergraduate engineering programs prepare students for a career in engineering by building knowledge of fundamental engineering concepts and developing skills in engineering design. Due to limitations on program credits, broadening the student's education beyond the required engineering coursework is typically limited to mandatory humanity and social science electives. Developing academic, professional and life skills can be a challenge due to the rigor of undergraduate engineering programs, yet these remain key factors in students' ultimate success and satisfaction with their careers. While students are expected to develop abilities to network with peers, teachers and professionals in the field, this skill is rarely taught explicitly.

Furthermore, degree accreditation boards, such as ABET, require accredited programs to achieve outcomes which include: an ability to function on multi-disciplinary teams; an understanding of professional and ethical responsibilities; the broad education necessary to understand the impact of engineering solutions in a global and societal context; a recognition of the need for, and the ability to engage in life-long learning; and a knowledge of contemporary issues. These outcomes are difficult to fully achieve in major courses alone.

In conjunction with a National Science Foundation-sponsored scholarship grant (NSF \#0631111), we have developed a program called MAX (Mentored Academic Experience) Scholars that addresses these needs. The engineering, engineering technology, math, biology and computer science students selected as MAX Scholars receive financial support and an opportunity to develop academic, professional and life skills through a weekly scholars' seminar. Interdisciplinary group work, peer mentoring and mentored research or internship experience are also incorporated into the seminar course and scholarship requirements.

Bates et al. (2010) provided an overview of the MAX Scholars program, details on the scholarship selection process, benefits for involved faculty and suggestions for implementing a similar program at other institutions. This paper will focus on the weekly seminar attended by the MAX Scholars and discuss its key successes in facilitating interdisciplinary group work across Science, Technology, Engineering and Math (STEM) majors, building community amongst the scholars, and helping them develop academic, professional and life skills. 


\section{Background}

The MAX Scholar program seeks to understand and address (1) the significant challenges facing students that contribute to decreased retention and to guide students through their STEM program; and (2) the need for connection and community for STEM majors across disciplines. These goals, combined with interdisciplinary experiences and overall academic and professional development, drive the structure and topics covered in the MAX Scholar seminar.

Literature, gathered from higher education, K-12, and organizational psychology, clearly supports the importance of community in influencing engagement and a broadening of cognitive performance beyond the purely technical (Goodenow, 1993a; Goodenow, 1993b; Ryan \& Patrick, 2001). Engineers with a broader world view will be poised to lead valuable technical innovation in the 21st century (National Academy of Engineering, 2005).

A greater sense of connection to community, ranging from the immediate (belonging) to the broad (affiliation) level can enhance retention, thereby delivering greater numbers of engineers and STEM scientists to the technical workforce. This theory is supported by the K-12 body of literature, where belonging and membership in the school community are proven to influence dropout rates (Center for Educational Statistics, 1993). In addition, higher education research cites lack of community (isolation) as a primary reason for women to leave engineering fields (Brainard \& Carlin, 1998) and connection to faculty community as a strong contributor to Hispanic student persistence in academic endeavors (Kraemer, 1997).

In contrast to the traditional view that attrition of STEM students was the result of a beneficial "weeding out" of inferior students from these difficult fields, Elaine Seymour states "We did not find switchers (from STEM majors) and non-switchers to be two different kinds of people. They did not differ by performance, motivation, or study-related behavior to any degree that was sufficient to explain why one group left and the other group stayed". In other words, "good" and "bad" students alike leave STEM fields. Therefore, noncognitive factors must play a role. Improvements in retention, resulting from increases in connection to community, are fundamentally supported by the higher education model of social integration developed by Tinto (1975, 1987, and 1993). Furthermore, a sense of belonging can result in increased feelings of security, stronger selfconcept, self-respect and coping abilities as these students move from academia to the workplace (DeNeui 2003).

\section{MAX Scholars Seminar}

One of the unique aspects of the MAX Scholars program is the focus on overall development of the scholarship recipients. The recipients, as defined by the program criteria, are diverse: multiple majors, male, female, nontraditional students, students with different ethnicities, religious affiliations, backgrounds, and family structure. The MAX Scholars attend a weekly seminar as part of the requirements of the program. The seminars are the primary mechanisms to build the academic, professional and life skills of the undergraduate scholars. In addition, students develop a sense of connection to the university and community amongst the scholar cohort. Finally, an investigative project completed by teams of scholars from different majors facilitates interdisciplinary discussions addressing broad science topics and builds relationships

amongst scholars. The weekly seminar plays a critical role in strengthening faculty-student 
interactions, facilitating peer mentoring, developing work/life balance skills, learning how to be both a leader and a member of an interdisciplinary team and building community. Figure 1 highlights the key input factors and output development for a MAX scholar.

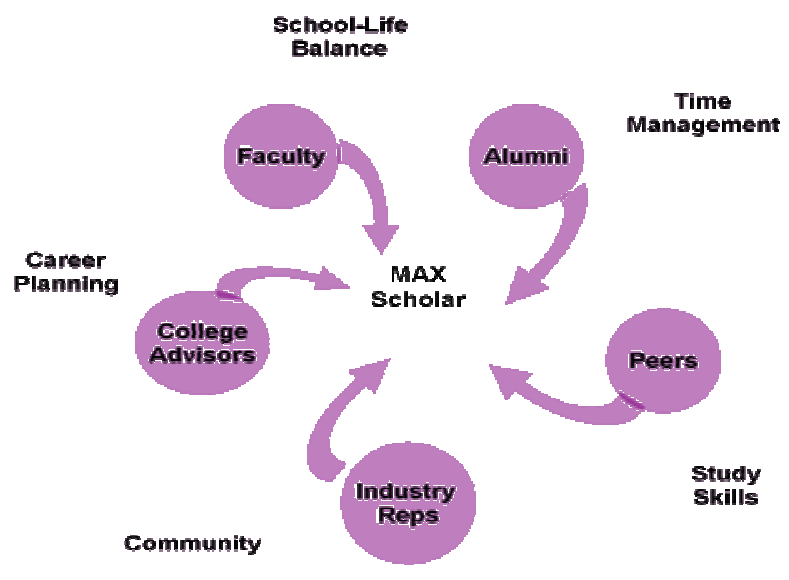

Figure 1: A model of the input factors and output skills gained by MSU MAX scholars.

Along with interdisciplinary project work, a typical set of seminars for a semester includes:

1) Introductions and assignment of reflection papers describing students' goals and obstacles

2) Resume formats and preparation

3) Preparing goals and small group discussion of resumes

4) Learning styles

5) Small group discussion of goals (grouped by year)

6) Job fair preparation and summer internship discussion

7) Interview skills with paired practicing

8) Mentoring

9) Guest speakers from industry and faculty

10) Study skills

11) Graduate school preparation

12) Assessing progress towards goals (grouped by year)

13) Interdisciplinary group projects

14) Work/life balance

Topics 3, 6 and 10 were all in small groups divided by major, allowing for stepping-stone peer mentoring. Other small group discussions were divided by class year or affinity groups based on learning styles, life situations or extra-curricular activities such as athletics. Several areas of scholar development achieved through the seminar are highlighted in the remainder of this section.

\section{Mentoring}

The MAX Scholar program strengthens faculty-student interactions through both the seminar and advising that occurs outside of the classroom. Peer mentoring (or stepping-stone mentoring) is used to address sophomores as they transition into the rigor of their advanced studies, juniors 
as they move into leadership roles and seniors as they enter the work force or graduate programs. The MAX Scholars are a leadership group that not only offer support for each other but also take on active, both formal and informal, peer advising that serves as a safety net for lower-division students. This net is typically built around study groups reinforced with active faculty mentoring and support for peer-mentoring. With the community of STEM scholars, we reinforce mentoring that is maintained after graduation.

\section{Interdisciplinary Teams}

The MAX Scholars are assigned a project each semester as part of the seminar course. The projects are completed in interdisciplinary teams of $3-4$ students each. For example, a typical team consists of students with various majors such as biology, math, computer science and engineering. Member selection varies but is designed to promote interdisciplinary group interaction. In previous years, the students considered various aspects of global warming after a research presentation about plants in the Antarctic by Dr. Christopher Ruhland (MSU, Biology). Another project was inspired by assigned reading, a novel with an environmental theme. During the following semester, students discussed ethical issues related to environmental science, with framework provided by Dr. Craig Matarrese (MSU, Philosophy). The students also developed academic advising modules to be presented to first year STEM students. These modules are currently incorporated into college advising seminars available for all students. The scholars take part in leading these seminars, helping develop their communication skills and supporting outreach goals. For each project, the groups were led by seniors who were responsible for organizing final presentations.

\section{Professional Networking}

A LinkedIn group called "MSU MAX Scholars" was created to help current scholars, alumni of our program, and faculty stay connected. The group is especially beneficial to alumni who are launching their careers and current students looking for mentoring or internship experiences. This resource helps them quickly build their professional network and stay connected with the MAX Scholars community. Throughout the year, the seminar helps scholars build networks by hosting speakers from industry, graduate school and alumni.

\section{Career Placement}

Topics related to career and graduate school preparation are covered during the weekly seminar. Setting goals, reflection on progress towards them, and writing resumes are fundamental topics. Outside speakers from industry, university services and alumni discuss interviewing skills, job negotiation strategies, and preparation for their early career years.

\section{Research/Internships}

MAX Scholars are encouraged to participate in either a research or internship experience during their educational years. Scholars engage with faculty and industry mentors on projects that apply their discipline to real-world problems. The program facilitates this through mentoring, networking and development of career placement skills. Scholars are strongly encouraged to present their research results or internship experiences at conferences, including our university Undergraduate Research Conference. Travel funds are available and encourage presentation at regional, national or international meetings. 


\section{Presentation and Communication}

Through the interdisciplinary group projects and research and internship experiences, MAX Scholars develop strong oral and written communication skills. In addition, students learn how to present for small and large groups, within and outside of their major.

\section{Work/Life Balance}

The seminar provides scholars with an opportunity to develop skills for success that extend and strengthen academic and professional development, facilitating personal development such as work/life balance skills. Seminar sessions include discussions on personal wellness such as nutrition and exercise. Active participation in a yoga session reinforces the need to maintain personal/professional balance during the rigor of academic pursuits. Each semester, the scholars are expected to attend an athletics or fine arts event on campus as a group. By "requiring" outside activities as part of the seminar work, students experience the benefit of engaging in social activities outside of their discipline and their established social networks. Additionally, we find that STEM students often strive for perfection and benefit by balancing studying with activities associated with quality of life.

\section{Life-Long Learner}

Awareness of the self as a learner and the development of metacognition improve the chances that a student will be a life-long learner. Along with projects on topics outside of their major, the seminar is used to discuss learning styles as it relates to the overall process of learning. The seminar, offered as pass/fail, provides an opportunity for the students to be engaged in learning without the pressure of receiving a letter grade. The interdisciplinary discussions on sciencerelated topics facilitated by the group projects have been a highlight for scholars. They have enjoyed the opportunity to learn and discuss science-related topics in a stress-free (i.e., gradefree) environment. The scholars also attend the annual Nobel Conference held at a neighboring college which hosts scientific presentations by prestigious researchers from all over the nation, providing an excellent opportunity for our scholars to grow as life-long learners.

\section{Conclusions}

There is a synergy between the recruitment, retention and professional development aspects of MAX student scholars. Professional development fuels retention of these students as they are encouraged by the life skill development and mentoring. Research/internship experiences, networking and career placement skills increase confidence and prepare students for a professional career. As these students share their enthusiasm and confidence with incoming students, a springboard for recruitment arises. For example, one of the scholar assignments was to prepare a presentation, both written and oral, on what they are passionate about in their major and how that area is connected to other STEM disciplines. Helping students articulate this serves as both a retention and professional development effort. Similarly, our scholars give a short presentation to introductory freshman orientation classes within their major. The underlying purpose of outreach activities is to help our MAX Scholars fully invest in their STEM major and future career, but it also plays a key role in recruitment of new STEM majors.

The MAX Scholar seminar could be implemented as a professional development seminar for programs with or without associated scholarships. While it may be difficult for engineering 
programs to connect with other majors, this type of program creates a space for students in biology, computer science and math as well as multiple types of engineering to interact. It offers true interdisciplinary experiences in a one credit seminar that could be more broadly incorporated into programs seeking to fulfill ABET criteria.

\section{Future Enhancements}

Through collaboration with the Iron Range Engineering (IRE) program and pending continuation of funding from the National Science Foundation, we plan to award approximately four scholarships per year to IRE students. Although granting MSU engineering degrees, the IRE program and its students are physically located in northern Minnesota at Mesabi Range College. These four scholarship recipients will be fully integrated into our MAX Scholars cohort. They will attend weekly seminars via interactive video feed and will participate in interdisciplinary teams. For example, a team working on a project and presentation would consist of 3 students in Mankato and 1 student in IRE. The team members will have to learn how to communicate and work together effectively despite the geographical separation. In today's marketplace, industry teams regularly consist of members at different company and client locations. Developing skills in distance communication and working effectively with people in different geographic locations will be a valuable asset for our scholars as they enter the marketplace or graduate school.

\section{Acknowledgments}

This material is based upon work supported by the National Science Foundation under Grant No. 0631111. Any opinions, findings, and conclusions or recommendations expressed in this material are those of the authors and do not necessarily reflect the views of the National Science Foundation.

\section{$\underline{\text { References }}$}

Bates, R., D. Nykanen, M. Hart, and M. Rahman (June 2010). Undergraduate Engineers and Interdisciplinary Peer-mentoring Groups. Proc. 2010 American Society for Engineering Education Annual Conference \& Exposition.

Brainard, Suzanne G. \& Carlin, Linda (October 1998). A Six-Year Longitudinal Study of Undergraduate Women in Engineering and Science. Journal of Engineering Education, 87(4), 369-375.

Center for Educational Statistics (September 1993), Dropout Rates in the United States- 1992, U.S. Department of Education, Office of Educational Research and Improvement.

DeNeui, Daniel L.C. (June 2003). An Investigation of First-Year College Students' Psychological Sense of Community on Campus. College Student Journal, 37, 224-234.

Goodenow, Carol (1993a). Classroom belonging among early adolescent students: Relationships to motivation and achievement. Journal of Early Adolescence, 13, 21-43.

Goodenow, Carol (1993b). The psychological sense of school membership among adolescents: Scale development and educational correlates. Psychology in the Schools, 30, 79-90.

Kraemer, Barbara A. (1997). The Academic and Social Integration of Hispanic Students into College, Review of Higher Education 20(2), 163-179. 
National Academy of Engineering (2005). Engineering Research and America's Future: Meeting the Challenges of a Global Economy, The National Academies Press.

Ryan, A. M., \& Patrick, H. (2001). The classroom social environment and changes in adolescents' motivation and engagement during middle school. American Educational Research Journal, 38(2), 437-460.Tinto, Vincent. (1975). Dropout from higher education: A theoretical synthesis of recent research. Review of Educational Research, 45, 89-125.

Tinto, Vincent. (1987). Leaving college: Rethinking the causes and cures of student attrition. Chicago: University of Chicago Press.

Tinto, Vincent. (1993). Leaving college: Rethinking the causes and cures of student attrition, Second Edition. Chicago: University of Chicago Press.

\section{$\underline{\text { Biographical Information }}$}

DEBORAH NYKANEN is an Associate Professor of Civil Engineering at Minnesota State University, Mankato. She has a Ph.D. in civil engineering from the University of Minnesota. Her focus areas include water resources, hydrology and hydrometeorology. She has 10 years of academic experience and is a registered P.E. in Minnesota.

REBECCA BATES received her Ph.D. in electrical engineering from the University of Washington. She is currently an Associate Professor in computer science at Minnesota State University, Mankato. She spent 2009-2010 as a Fulbright Scholar in Brazil. Her favorite class to teach is Artificial Intelligence \& Science Fiction.

MARILYN HART has a Ph.D. in Cellular and Molecular Biology from St. Louis University School of Medicine and was a postdoctoral fellow at Washington University School of Medicine. She is currently an Associate Professor in Biological Sciences at Minnesota State University, Mankato and Director of the Undergraduate Research Center.

MEZBAHUR RAHMAN is a Professor in Mathematics and Statistics at Minnesota State University, Mankato. He received his Ph.D. in applied statistics from the University of California Riverside. His research interests are parametric and non-parametric statistical inferences including estimates and tests for parameters and distributions. 